\title{
TOWARDS AN ENGINEERING FRAMEWORK FOR NETWORKS OF FIRMS
}

\author{
Ali Zaidat, Lucien Vincent, Xavier Boucher \\ Ecole des Mines de Saint-Etienne - Centre SIMMO \\ 158 cours Fauriel,42023 Saint Etienne Cedex 2, FRANCE \\ [ zaidat, vincent, boucher @emse.fr
}

\begin{abstract}
The main objective of our research work is to contribute to the development of a modelling framework aiming at the engineering and integration of networks of firms(NoF). Referring to a state of the art on networks engineering, we first show that such a framework should provide a support for the management of networks' evolution in the future. Based on a structural study of networks of firms $(\mathrm{NoF})$, in the paper we identify structural mechanisms and then configuration factors useful as a basis for networks engineering. Those configuration factors will be presented and linked to "state variables" and "contingency variables". Both kinds of variables are to be later exploited to develop an architecture and a methodology for engineering and integration of NoF.
\end{abstract}

\section{INTRODUCTION}

The Industrial context is characterized by the emergence of new organizations induced by lots of factors like market globalization, short product life cycle, high variability of customer demand, need of higher flexibility and reactivity, or quick development of information technologies. Extended enterprise, virtual enterprise, supply chain, ... are examples of such new organizations. We call them " networks of firms " in this article.

Networks of firms(Nof)are complex and dynamic systems. They constitute a recent field of research and they are a major center of interest for enterprises. To answer that preoccupation among managers, lots of research has been launched, most of them in collaboration between enterprises and the scientific community. Those projects aim at studying the behaviour of that new type of organization and at developing methods and tools to support the management of their creation and evolution. This research either remains general and deals with all domains of the network, or focuses on a specific point of view. Some of the prominent projects which study the SME networks are Grecopme (Groupement d'Entreprises COpérantes), PLENT (Planning Small Medium Enterprise Networks), and UCANet (Understand the Consequences of the Adoption of tools and systems to support dynamic Networked and virtual organisations). The projects NIIIP (National Industrial Information Infrastructure Protocols), MARVEL OUS, VEGA(The Virtual Enterprise using Groupware tools and distributed Architecture), PRODNET 
II (Production Planning and Management in an Extended Enterprise) aim at the development of information systems. The projects X-CITTIC (Planning and Control System for Semiconductor Virtual Enterprises), virtual organisations in Logistics, IMS (Intelligent manufacturing Systems) focus on the creation and the management of NoF and more particular of virtual enterprises. With an important synthesis of several work in this field, the project UCANet points out that the subjects studied are : product life cycle, networking organisation life cycle, kind of realised product and focus (organisation models, ICT architectures, tools and human resources).

In spite of good results in that field, complementary developments are required to give a concrete decision support to $\mathrm{NoF}$ engineering and integration. Our research focuses on that question: its main objective is to contribute to the development of a modelling framework aiming at the NoF engineering and integration.

In the mark of this large perspective, this paper aims essentially at one particular goal : to identify "characteristic variables" of networks. Such variables are necessary to build the models later used as support for an engineering methodology. Section 2 defines what we mean by evolution of Nof. Section 3 presents a synthesis of a NoF structural study. This study is used in section 4 to identify configuration factors related to more precise "characteristic variables".

\section{EVOLUTION NOTION OF NETWORKS OF FIRMS}

A network of firms is a set of organizations which combine their resources and processes around a common predefined purpose. The difficulties encountered in managing different partners and the dynamic evolution of the environment make $\mathrm{NoF}$ more complex and more dynamic than classical organizations. Therefore, the engineering processes and integration processes are very important in the life cycle of the network [Vesterager et al. 2001]. The following figure describes the notion of "networks evolution" with a schematic illustration based on [Strader et al. 1998].

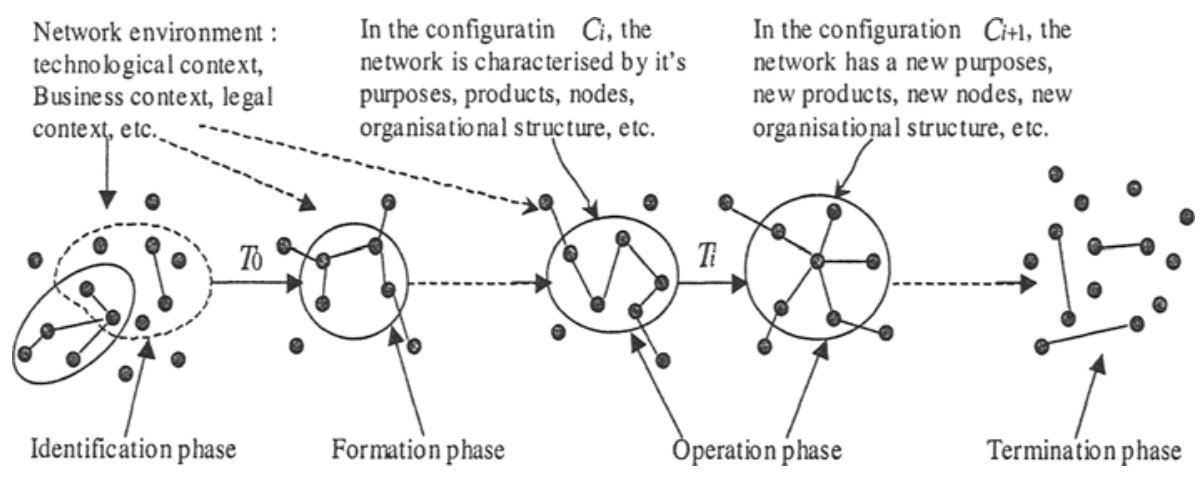

Figure 1 - Notion of evolution for NoF

A network of firms can be characterized by (1) a set of state variables used to provide a model of its configuration $C_{i}$ at a specific date $t_{i}$ and by (2) environment 
variables which are necessary to describe its context. $T_{i}$ is a model of the transition of the system from the configuration $C_{i}$ to the configuration $C_{i+1}$. Such a change results from the reaction of the decisional system to internal problems of the network and to external events coming from the environment.

To explain the evolution of a system, [Meinadier 2002] defined a decomposition approach based on temporal invariance level. This approach use components of the system behaviour description. For the author, the characteristics of systems can be classified by their speed of evolution or invariance period. They can be gathered on invariance temporal levels which are classified by their degrees of stability. This approach seems relevant to study the evolution of Nof (see section 4 ). So it is important to describe the relation between the state variables and these levels in the network. Such relations are highlighted in section 4.

The life cycle phases of systems are considered as the more stable invariance temporal level. Virtual enterprise life cycle developed by [Strader et al. 1998] presents a global vision and a synthesis on NoF life cycle. The authors identify four main phases : identification, formation, operation and termination as we indicate in figure 1 . However, the life cycle developed in this work remain very generic, and a deeper and more detailed study is necessary for those four phases.

Nevertheless, to respect the limits of that paper, we will not develop the whole life cycle notion. It is first necessary to identify the formal characteristics of NoF that we will later use to present a life cycle model. The identification of such formal characteristic requires a structural study of networks of firms, as we develop in section 3

\section{STRUCTURAL STUDY OF NETWORK OF FIRMS}

In this section, we specify structural mechanisms used to split work into distinct tasks and to coordinate these tasks in NoF. These mechanisms will later contribute to identify state variables. These mechanisms make the internal organization of the NoF explicit. They constitute generic knowledge on such systems and provide us with a basic description of the organizational structure.

For [Mintzberg 1982] «the organisation structure can be easily defined as the total sum of mechanisms used to split work on different tasks and further to insure the coordination between these tasks». This definition which we choose is rich and includes almost all characteristics of the others definitions in this field [Livian 2000].

The basic mechanisms of coordination in the traditional organization (see table 1) remain valid and useful for the NoF. We find them under the same definition, even if they are applied in a lightly distinct way; but to fullfil the requirements of our framework, we further identify new structural mechanisms : partner selection, contract, socialization, competence coordination, and knowledge standardization. 
Table 1- Structural mechanisms in NoF

\begin{tabular}{|l|l|}
\hline $\begin{array}{l}\text { Structural } \\
\text { mechanisms }\end{array}$ & Description \\
\hline $\begin{array}{l}\text { In traditional } \\
\text { organization }\end{array}$ & $\begin{array}{l}\text { Mutual adjustment, direct supervision, standardization of work process, } \\
\text { standardization of outputs, and standardization of employee skills. } \\
\text { [Mintzberg 1982] }\end{array}$ \\
\hline $\begin{array}{l}\text { Partner } \\
\text { selection }\end{array}$ & $\begin{array}{l}\text { NoF have to co-ordinate processes among selected firms partners. The } \\
\text { partners' selection process is required either when adding new partners or } \\
\text { when choosing the right partners to carry out the activities of the network. }\end{array}$ \\
\hline Contract & $\begin{array}{l}\text { The contract represents a formalization and a guarantee of commitments for } \\
\text { the partners. It specifies the purpose of the network, products, relations } \\
\text { between partners, and provides mechanisms for conflict solving. }\end{array}$ \\
\hline Socialization & $\begin{array}{l}\text { [Schein 1968] defines socialization as the process used by a new arrival to } \\
\text { learn the values of a system, the norms and the behaviour of a society or a } \\
\text { group that he wants to join. In the case of international networks, the } \\
\text { cultural differences between the partners who are scattered in the world } \\
\text { confer this mechanisms an important value in the cohesion of the network. }\end{array}$ \\
\hline $\begin{array}{l}\text { Competence } \\
\text { coordination }\end{array}$ & $\begin{array}{l}\text { The competence coordination is a generalization of qualification } \\
\text { standardization used in the traditional organizations. The competence of } \\
\text { partners could be used as a guarantee of the results of their activities. }\end{array}$ \\
\hline $\begin{array}{l}\text { Knowledge } \\
\text { standardization }\end{array}$ & $\begin{array}{l}\text { The knowledge standardization allows partners to have a clear and shared } \\
\text { definition of different common concepts handled in the network. This } \\
\text { knowledge can be a means of formalization of common tasks and a means } \\
\text { of collective learning. }\end{array}$ \\
\hline
\end{tabular}

The description of the structural mechanisms (mechanisms for splitting work and for coordination) specific for NoF is a first and an important step in order to identify consistent and relevant modelling variables. Indeed, as we show in the following section, those mechanisms induce what we call "configuration factors", that we link to state and contingency variables.

\section{CONFIGURATION FACTORS}

This section aims at identifying the necessary concepts for configuration modelling of NoF. We propose to refer to the design model of the figure 2 :

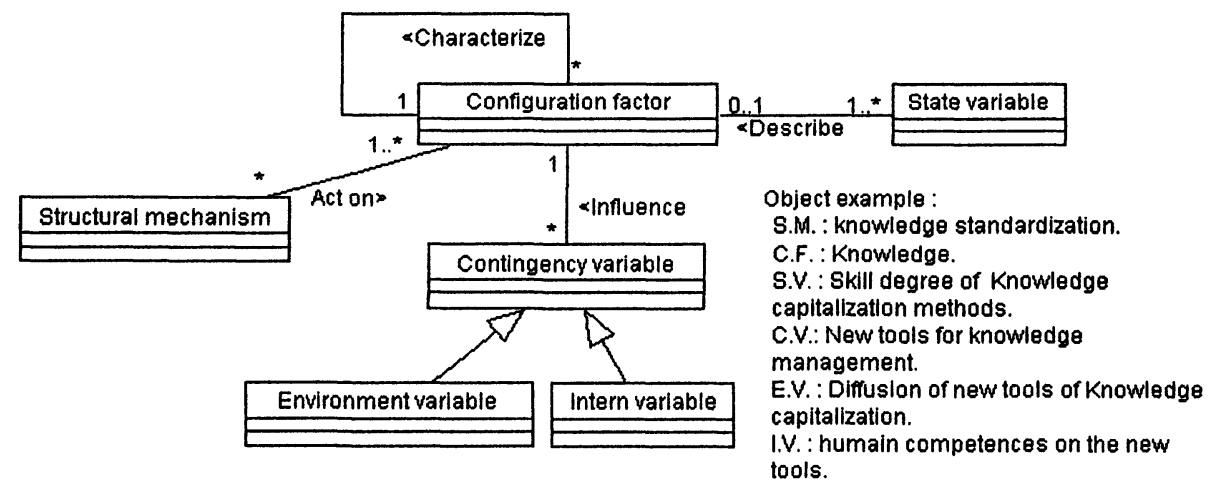

Figure 2-Class diagram of configuration modelling concepts of NoF. 
The configuration factors are macro-variables of the network. They could be seen as views or domains which characterize the network. They are characterized by configuration sub-factors and state variables, and influenced by contingency variables.

Contingency variables are the elementary characteristics of the network and the environment that influence the definition of state variables. They consist of environment variables and network internal variables.

Variables are elementary concepts of description of NoF. They take values within specific domains. State variables provide a model of the network at given time and deliver the necessary information to control it. They could belong to the set of internal variables but we also find in this set variables on which we can not act.

In order to identify configuration factors we first refer to the work on network typology. Each one of the following works use different characteristics. In the Grecopme project the SME networks are classified through complementary activities and similar competences. [Camarinha et al. 1998] used the variables: duration, topology, participation, coordination and visibility. [Grandori et al. 1995] studied different kinds of inter-firm networks. They proposed a based typology on symmetry and formalization degree of relations. [Ettighoffer 2000] use for his classification the degree of cooperation and integration on terms of resources, information system and cooperation processes. The members of project UCANet classified SME networks by the important production activities with consideration to the degree of design and their strategic relationships with their different kinds of economic partners.

Furthermore, we refer to research works on the operation and the evolution of NoF. [Shao et al. 1998] described the virtual enterprise through four dimensions: connectivity, purpose, technology and boundary. However, [STRATEGOR 1997] used cohesion, combinative and activation modes (power used to create a new link). [Cohender 1996] is interested in the emergency and evolution of the network; he used graph theory and introduced the concepts of connectivity, irreversible state, etc.

Lastly, in structural study of virtual enterprises, [Saabeel 2002] identified the following variables : goal-specificity, formalization, modularity, heterogeneity, time and spatial dispersion, purpose, connectivity, boundary, technology, complexity or diversity, uncertainty or unpredictability, and interdependence.

All those works, except [Saabeel 2002], do not deal with the specific problem of NoF engineering. So, we have completed these works by a deep study on this application field. The configuration factors and associated variables are also deduced from structural mechanisms identified in section 3.

To point out the relations of configuration factors and associated variables with the notion of evolution it is necessary to study their relations with behavioural view of the network. So we decide to apply the system decomposition approach based on temporal invariance level [Meinadier 2002], as announced in section 2. As result we identified four temporal invariance levels relevant to our application field : strategic aspects, domain, process and activity. The following figure shows these levels with associated configuration factors and variables. A structural and behavioural views are necessary to study the evolution of systems. In the figure, the organizational structure appears at the level of domain. Such a choice is justified by the fact that each domain could have its proper structure. Whereas The behavioural view is described by temporal invariance levels. 
The figure show that changes in the characteristics of the level $i-1$ cause variations on the level $i$ and the evolution rules of its characteristics depend on the more permanent characteristics of the level $i+1$.

Tables 2 defines configuration factors, state variables and internal variables of NoF.

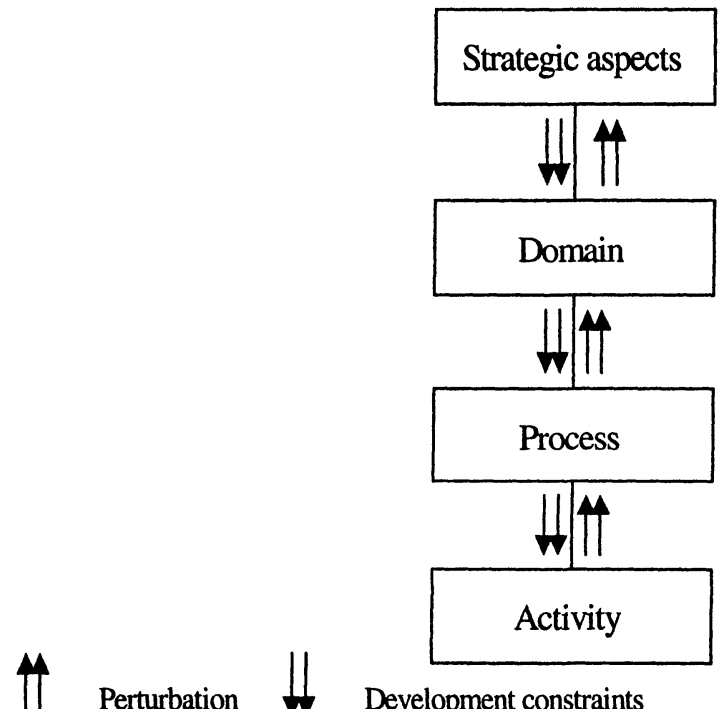

Strategic aspects are purpose, size, geographical dispersion, duration, relation, product, partner, stability, conectivity...

A domain can be characterized by organizational structure, organizational maturity, $\ldots$

A process can be characterized by product, ICT, knowledge, culture, logistic, ...

An activity can be characterized by product, ICT, knowledge, culture ...

Figure 3 - Configuration factors, associated variables, and evolution diagram.

Table 2 - Configuration factors, state variables and internal variables of NoF.

\begin{tabular}{|c|c|}
\hline $\begin{array}{l}\text { Configuration } \\
\text { factors }\end{array}$ & Description \\
\hline $\begin{array}{l}\text { Purpose of the } \\
\text { network }\end{array}$ & $\begin{array}{l}\text { This purpose defines why the NoF exists in terms of value that it can } \\
\text { deliver. }\end{array}$ \\
\hline Size & $\begin{array}{l}\text { The size of an network can be expressed by the number of partners and } \\
\text { business volume. }\end{array}$ \\
\hline \begin{tabular}{|l} 
Geographical \\
dispersion
\end{tabular} & $\begin{array}{l}\text { The partners can belong to the same locality, the same region, the same } \\
\text { country or are scattered in the world[Poulin et al. 1994]. }\end{array}$ \\
\hline Duration & $\begin{array}{l}\text { The network can have a project life duration for what it is created, long and } \\
\text { predefined life duration or long and not predefined life duration. }\end{array}$ \\
\hline Relation & $\begin{array}{l}\text { Relation type refers to cooperation relations and transactional } \\
\text { relations[Livian 2000]. Symmetry of relations can be explained by the } \\
\text { interests and stakes of the network for each partner[Grandori et al. 1995]. }\end{array}$ \\
\hline Product & $\begin{array}{l}\text { The product type makes the important activity types of the network } \\
\text { explicit. Networks with specific product and networks with standard } \\
\text { product (with some variants) differ by their purposes, organization } \\
\text { structures and evolution cycles [UCANet 2001]. }\end{array}$ \\
\hline \begin{tabular}{|l} 
Partner \\
\end{tabular} & $\begin{array}{l}\text { A partner can be described by the following attributes: Attractivity } \\
\text { (competences, capacity, culture, etc.), motivation (learning and transfer of } \\
\text { knowledge, increase competitivity, etc. ), purpose, legal and financial } \\
\text { characteristics, geographical location, specificity of the credits and its roles } \\
\text { in the network (customer, supplier, the both or neither). [GLOBEMAN21 } \\
\text { 1999][Williamson 1994] }\end{array}$ \\
\hline
\end{tabular}




\begin{tabular}{|l|l|}
\hline Stability & $\begin{array}{l}\text { Its structure is said fixed when we have the same partners in the whole life } \\
\text { cycle of the network except rare cases. It is said dynamic when partners } \\
\text { can leave or join the network[Camarinha et al. 1998]. }\end{array}$ \\
\hline Connectivity & $\begin{array}{l}\text { Connectivity expresses all possible relations between partners in the } \\
\text { network. It has a fixed configuration when partners have specific roles and } \\
\text { we can not build other relations. It has a weak combinative when there are } \\
\text { few possibilities to combine partners' working together. It has a strong } \\
\text { combinatory when there are a lot of possibilities. [STRATEGOR 1997] }\end{array}$ \\
\hline $\begin{array}{l}\text { Organizational } \\
\text { structure }\end{array}$ & $\begin{array}{l}\text { The network can adopt a process structure, a functional structure or a } \\
\text { hybrid structure. }\end{array}$ \\
\hline $\begin{array}{l}\text { Organizational } \\
\text { maturity }\end{array}$ & $\begin{array}{l}\text { Trust, cohesion, integration, ... that existed between partners have an } \\
\text { important influence on the future form of the network. }\end{array}$ \\
\hline ICT & $\begin{array}{l}\text { It is interesting to evaluate the level of integration of the partners' } \\
\text { information systems referring to complexity of middlewares, use of } \\
\text { standards (XML,...), data base architecture, and communication } \\
\text { architecture. }\end{array}$ \\
\hline Knowledge & $\begin{array}{l}\text { It is important to know if the network possess a process of building up } \\
\text { knowledge, an ontology (it can be informal, semi-informal, semi-formal } \\
\text { and formal[Dieng et al. 2000]), and a memory[Van Heijst et al. 1996]. }\end{array}$ \\
\hline Culture & $\begin{array}{l}\text { The culture management aims to promote cultural values and cultural } \\
\text { standards in the network [Loeser 1999]. The culture can be partly described } \\
\text { by a set of rules, used to develop a common behaviour within the different } \\
\text { communities of the network. }\end{array}$ \\
\hline Logistic & $\begin{array}{l}\text { Logistic in the network can be defined as the process of planning, } \\
\text { implementing and controlling the efficient cost-effective flow and storage } \\
\text { of raw materials in the supply chain. [TELEflow 1999] }\end{array}$ \\
\hline
\end{tabular}

\section{CONCLUSION}

Our work aims to develop a framework for $\mathrm{NoF}$ engineering and $\mathrm{NoF}$ integration. In this article we have presented the results of the first step of our process research. We have identified configuration factors and associated variables of NoF. These results are based on a state of the art on NoF, engineering methodologies, integration methodologies, and on the structural study of NoF. Configuration factors are macrocharacteristics of the network. Contingency variables are the characteristics of the current situation that influence the definition of the state variables (see section 4) in every creation or change project of NoF. The specification of configuration factors is not yet achieved. We have identified most of them but the specification of configuration sub-factors, state variables, and contingency variables has to be more detailed. This specification will be the subject of a future article.

To develop a framework for NoF engineering and NoF integration we have decided to use and to specify the GERAM framework. This framework is a metamodel that we can apply for any organization. In the near future, we will present concepts to model, the life cycle, the modelling framework, and the methodology related to NoF. 


\section{REFERENCES}

1. Camarinha-Matos L.M., Afsarmanesh H. 1998: Virtual Enterprises : Life cycle supporting tools and technologies.To appear in Handbook of Life Cycle Engineering: Concepts, Tools and Techniques, A. Molina, J. Sanchez, A. Kusiak (Eds.),, Chapman and Hall, pp. 1-30.

2. Cohender P., Jacot J. H., Lorino P., 1996 : Cohérence, Pertinence et Evaluation; Economica.

3. Dieng R., Corby O., Giboin A., Golebiowska J., Matta N., Ribière M., 2000 : Méthodes et outils pour la gestion des connaissances. Editions Dunod, Paris.

4. Ettighoffer D., Van Beneden P., 2000: MET@-ORGANISATION, les modèles d'entreprise créateurs de valeur ; Editions Village Mondial, Paris.

5. GLOBEMAN21 1999: Descriptive parameters for the network and the virtual enterprise. Study report, Global Manufacturing in the 21st Century, pp. 1-15.

6. Grandori A., Soda G., 1995 : interfirms networking; in organizational studies, pp. 16-2.

7. Loeser B.O., 1999: How to Set Up a Cooperation Network in the Production Industry: Example of the Huber + Suhner AG. Industrial Marketing Management, Volume 28, Issue 5, pp. 453-465

8. Meinadier J.P., 2002 : Le métier d'intégration de systèmes, p50. Editions LAVOISIER.

9. Mintzberg H., 1982 : Structure et dynamique des organisations. Les éditions d'organisation, Paris.

10. Poulain D., Montreuil B., Gauvin S., 1994 : Bâtir oujourd'hui l'organisation de demain ; Montréal (Québec).

11. Saabeel W., Verduijn T.M., Hagdorn L., Kumar K., 2002 : A Model of Virtual Organisation: a Structure and Process Perspective. Electronic Journal of Organizational Virtualness, pp. 1-16.

12. Schein, E.H., 1968 : Organisationnal Socialiszation and the Profession of Management. Industrial Management Review, pp. 1-16.

13. Shao Y..P., Liao S.Y., Wang H.Q., 1998: A model for virtual organizations, Journal of Information Science 24(5), pp. 305-312.

14. Strader T.J., Lin F.R., Shaw M.J., 1998: Information infrastructure for electronic virtual organization management, Decision Support Systems, Volume 23, pp. 75-94

15. STRATEGOR, 1997: politique générale de l'entreprise, stratégie, structure, décision, identité. "STRATEGOR » est l'équipe des professeurs du département stratégie et politique de l'entreprise du groupe HEC de Jouy-en-Josas.

16. TELEflow(Telematics supported workflow analysis and business process enhancement)1999 : Deliverable 3.2, http://www.atm-computer.de/teleflow/.

17. UCANet 2001 : Pilot cases of SMEs networks. Study report, programme Information Society Technologies, http://web.democenter.it/ucanet/publicDocs.php

18. Van Heijst G., Van der spek R., Kruizinga E., 1996 : Organizing Corporate Memories. In B. Gaines and M. Musen (ed.), Proceeding for the 10th Banff Knowledge Acquisition for Knowledge-Based Systems Workshop (KAE'96), Banff, Canada, pp. 42-1/ 42-17.

19. Vesterager J., Bernus P., Pedersen J.D., Tølle M., 2001: The what and why of a Virtual Enterprise Reference Architecture. Published in: "E-work and E-commerce - Novel Solutions and practices for a global networked economy", eds. Brian Stanford-Smith and Enrica Chiozza, IOS Press, , pp. 846852.

20. Williamson O.E., 1994: Les institutions de l'économie. Paris, InterEditions. 